\title{
Role of Transformative Learning Interventions in Developing Conducive Environment for Female Adult Learners in Higher Education
}

\author{
a Muhammad Shabbir, Sajid Masood, ${ }^{\mathrm{c}}$ Ghazal Khalid Siddiqui \\ ${ }^{a}$ Assistant Professor, Govt. College University, Faisalabad, Pakistan \\ Email: mskhalid6o6@yahoo.com \\ ${ }^{\mathrm{b}}$ Assistant Professor, University of Management \& Technology, Lahore, Pakistan \\ Email: sajid@umt.edu.pk \\ ${ }^{c}$ Assistant Professor, University of Education Lahore, Pakistan \\ Email: ghazalkhalid@ue.edu.pk
}

\begin{tabular}{l}
\hline ARTICLE DETAILS \\
History: \\
Accepted: 20 April 2020 \\
Available Online: 15 June 2020
\end{tabular}

Keywords:

Adult learners, Transformative

Learning, Conducive

Environment for Learning, Interventions

JEL Classification:

I2O, I21, O13

DOI: $10.47067 /$ reads.v6i2.217

\section{ABSTRACT}

The increasing number of female adult learners required a need for a deeper and more additional background related consideration on the effects contributing toward educational achievement for the learners who return to study. The aim of this study is to define the role of Transformative Interventions in developing Conducive Learning Environment for female adult learners in higher education with the consideration on hindrances faced, as they re-engage and continuing their post-compulsory educational passage. Qualitative approach with explanatory case study design has been employed to conduct this study. Semi-structured open-ended interviews conducted for 16 purposefully selected female participants. Two private and two public universities were selected from which adult working students and experienced of having transformative learning interventions during their course. Moreover, the experiences and responses highlighted the needs, hindrances and expectations of the adult students in higher education. They identified reflective activities including article review and reflective writing, faculty support, seminars, educational conferences, presentations, projects on real life issues, discussion and introducing demanding courses are the important transformative learning interventions for developing Conducive environment for adults. The major factor responsible for developing Conducive environment was experiences and exposure by the adult learner and providing opportunities through the Andragogy and expertise. Notes on interviews and reflection journals were utilized to triangulate data to support these methods. Data analysis and results of the study indicated that participants experienced transformative learning interventions through both educational and non-educational related activities held in university by Higher Education.

(C) 2020 The authors. Published by SPCRD Global Publishing. This is an open access article under the Creative Commons AttributionNonCommercial 4.0 


\section{Introduction}

Maria was a bright student in school who passed her matriculation successfully and took admission in Intermediate. But she was discouraged for continuing college by her parents, with the reason that they were not educated and had no backup because she was their elder child. She got married earlier and had two children but her marriage broke down. She was again dependent on her parents for look after herself with two children but she knew that they were unable to do so. She had little qualifications and no work experience for the job so she realized that she would have to do an admission in studies for the development of her career. She had difficulties to attend the college regularly with punctuality as there were no childcare facilities in University. She did her graduation privately with good marks and gained a place to study in university for masters. Maria extremely felt that there was a great difference between herself and other students because of her age and financial entitlements. By the beginning of $2^{\text {nd }}$ semester, Maria began to learn to use the computer to complete assignments but she had a serious problem to spend money on courses for learning computer programming and Internet. She had facility to do her work in computer lab in University but she had a problem in managing the time for spending more after classes at University in computer lab. She felt lonely among the class because of her age and difficulties as no one helped her. In spite of many difficulties, she passed in B grade and completed her course effectively with success. When she looking back, she found that she survived in spite of less support and facilities offered to her as an adult student in university. She decided to stop her study after M.A and looking for job. But it was very difficult to have a job because of her age and gender even after gaining a degree; she didn't have experiences of transformation. Her qualification was traditional and it not comprise with the modern and updated demands of the job market.

The next inspiring non-traditional adult student is Samra who is an elder member of middle class family started his job as a clerk in administration department of a public University. She was just graduate so had many difficulties in maintaining herself due to globalization and technology advancement. She did few online diplomas for increasing his efficiency in computer programming as she found that technological competencies lead in achieving high levels in personally, socially, academically and professionally success. She married and had three children so she wanted to support and facilitates her family by increasing income with the promotion in job designation. She took admission in her own university in evening classes in Master's program for working students. She tried to balance his job and education. But in the $2^{\text {nd }}$ semester, the timings of classes would be changed and classes started one hour earlier before the regular class timings due to change in weather. Samra had trouble with job timings to get take off from job one hour before. She requested her management to grant permission to leave the job one hour before. They granted the time and restricted her to complete the work in extra hours and not to join again in any further program for study during job. She also restricted by the university to attend the required regular classes at time to complete the targeted credit hours. She suffered to maintain the required regular timings of credit hours which were very difficult to manage the overburdened office assignments completions. Samra struggled under the strain of juggling parenting, work and university, as many working students do. At last, Samra successfully completed her course and earned master's degree which helped her to get promotion in job as Assistant to Head of the Department with an attractive salary package. But when she remembered the learning period in University with difficulties of age, married life, job, and expectations from organization where she worked, rigid \& strict rules, regulation and policies of higher education, nevertheless the reason for working to meet multiple and sometimes contradictory immediate requirements of the roles as student, employee, and parent. Sometimes, it creates high level of stress and anxiety which make it less likely that students will complete their course for degree with keen interest and motivation. She only qualified 


\section{Review of Economics and Development Studies, Vol. 6 (2) 2020, 391-40o}

with the formal education degree but didn't learn any kind of transformation which is the need and requirement of her job.

To cope with these challenges the implications and knowledge of transformative leaning and its interventions is required from university and teachers. All the adult students without the discrimination of gender and age will do their course in effective and useful way with the support of their teachers (Andragogical knowledge), maintain their balance in work place (University's rules, regulation and policies) and learning environment (Transformative learning interventions) and change their structures analytically reflecting on beliefs and find new ways of defining their world of perception (Transformative learning).

\section{Background of the Study}

The population of Asia has distinctive importance and scope because of its size, natural resources and planned location and it is also more meaningful as a "cultural concept". From the last two eras, Asia accomplished dynamic economic growth and a high level in innovation \& creativeness in entrepreneurship of different sections. Asia comprises with five high populated developing countries in the world that are Bangladesh, China, Indonesia, India and Pakistan. Many researchers and studies try to understand the reasons and suggestions on half of the world 'population and three quarters of the non-literate adult population of the world. For periods of time, the focus point of academic studies has been trying to find out the effects contributing to educational success for adult learners. On the other hand, research concerned with the need for profounder and contextualized understanding of those impacts that has been less evident. Many researches included the examination of impact of effects as single phenomena, for example, availability of flexible programs, and in the single perspective, experiences of adult learners balancing multiple roles in conflict situations in the demands of academic studies.

The rights on the adult education are accepted by maximum government constitutions and in national laws which are reproduced in various international declarations and agreements. For example, Universal Declaration of Human Rights, 1966 International Covenant on Civil and Political Rights and International Covenants on Economics, Social and Cultural Rights (UNESCO, 2008). The UNESCO International Conferences held on Adult education in Elsinore in 1949 mentioned in Field (2016), and many other regional and national proceedings were helpful in renewing governmental, national and international commitments, participate in advance thinking and develop policy \& actions plans on the education of adults.

The adult learners characteristics facilitate in attaining different precise aims and goals related to education. When the learner become adult, there is not a change in their needs only but there is a need to develop the learning process as well in relation of the requirements. There is a need to understand and know about the adult who "selects to accept primary responsibility for planning, implementing, and evaluating his/her own learning”. (Merriam and Brockett, 2007, p. 35).

This adult phase described as "emerging adulthood (when adolescence is ending) to the end of life" (Bjork Lund and Bee, 2008, p4). They divided the period of adult learning into four main groups; initial adulthood ranging from 20 to39; middle adulthood ranging from 40 to 64 ; older adulthood ranging from 65 to 74 ; and the late adulthood from 75 as above. Additionally, they distinguish advanced lifespan in further three phases classify accordingly with ages as young-old (65 to75), old (65 to 75), and oldestold (85 and older); considered as the significant division assumed the rapid and reliable increase in the adult population. 
Some studies described half from the total enrolment of nontraditional students are at the average age of 30 years (Aslanian \& Brickell, 1990). Researches related to adult learners described that they concerned with accomplishments, encouraged with identified factors in career advancement and require learning plans and programs that facilitates and support them, and efforts with their learning commitments. Continuing education after a break involves progress in the direction of well-defined distinctiveness from the part of an adult learner. Adult learners require balancing between participation in a novel developed personality and holding on to structured identity.

\subsection{Adult Learners in Higher Education}

A vital drift has an important influence on registration and retention of the adult students in higher education is displaying the "changing life cycles as our nation's population ages" (Yankelovich, 2001, p. 8). The adult learners to be known with a various range of titles including non-traditional student, adult student, returning adult, adult returner, mature learner and various other are used for adult learner and they also have a broader range of cultural and educational backgrounds, abilities, responsibilities and experiences.

\subsection{Transformative Learning Theory in Educational Institutions}

Mezirow (1981, 1994, and 1997) described that transformational learning create available possibilities for the attainment of transformation in learner with the combination of other kinds of learning, special experiences that are useful in form the learner thoughts and create a noteworthy influence in a paradigm shift which affects the learner 's consequential understandings (Clark 1993). Through the Mezirow's theory, transformational learning in the classroom were highlighted on the subject to direction of involvement, analytical reflection and rational dialogues. Perspective transformation practice is appropriate for the development of critically consciousness for how and why beliefs have come to provide variations for the perception, understanding the sense of the world; of reframing the suppositions to authorize more comprehensive, selective, absorptive and assimilative perception; and of creating conclusions or if not then performing on these new considerations. These wide-ranging, discerning absorptive and integrative are better viewpoints for adults select if they can because they are encouraged for recovered and comprehend sense of their knowledge (Mezirow, 1991, p.14).

As a constructivist, Jack Mezirow (1994) defined transformational theory in holding position to the ways in which learners understand and comprehend intelligence through the involvement necessary to constructing reference and understanding. Transformational learning modifies the frame of reference and suppositions through which a learner can understand and realize the world. A belief system covers two structures; one is behaviors of attention and second is an opinion. Belief system exaggerated and formed by views construct about cultural, social, educational and political events. But, an actual standpoint creates in their belief system (Mezirow 1997). When learner begins analytically reflect and discover planned suppositions and dogmas, they become more visible, comprehensive, insightful and intense to transformation (Lehman, 2003).

\subsection{Encouraging learning environments through the interventions of transformative learning}

During course, educator may function in many roles: teacher, guide, mentor, and colleague. Their educators are charged with rising as much learning as possible: teaching skills, providing knowledge, and fostering personal and professional growth. This is essential to provide carefully planned activities and interventions for transformative learning and growth. Disagreements in perspectives, allow students and teachers reflect on transformative learning experiences. 
Over the past decade, interest in practice of transformational learning increases in the fields of adult learning and higher education. If higher education provides transformative learning and the assurance of perspective transformation to the forefront of its function, faculty and staff must bring it in their practice, as distinguished from theory. Transformational learning must essential for understanding, distinguishing, and reflecting possibilities for consequences, and intentionally employed strategies for assisting transformative learning in experience of the learner.

Practices of transformative learning focused on speculative content and applied activities encourage the methods for expressing acute concern and reflection in adult learners. The some of the following educational interventions that are effective in promoting transformative learning are considered analytically reflective; Case Study, Collaborative Learning Activities, Collaborative Writing Projects, Critical Incidents Experiences, Discussion on Real life Issues, Interviews, Discussions, Student Presentations, Seminars, Educational conferences, Journals and Research Papers (King, 2005).

\section{Study Objective}

This study is aimed at conducting a research to describe needs and hindrances confronted by adult learners in higher education along with determination of concepts andragogy and transformative Learning. This study also aims to interpreted the learning experiences described by the study participants through the lens of Mezirow Transformational Learning Theory. And to generate suggestions for better conceptual understanding the role of Transformational Learning Interventions in making the learning and teaching more effective with developing Conducive Environment. Moreover, to encourage educationists to discover possibilities for transformational learning and its interventions in processes, practices, and environment for adults.

\section{Research Methodology}

\subsection{Research Design}

This study is adopting a qualitative descriptive case study and using purposeful sampling in order to choose its sample. The study is limited to exploratory case study with the experiences of transformative learning interventions during the course in university as it would be more investigative through the outside or indirect activities from university.

\subsection{Population of the study}

Population is female adult employed students from age 26 and above; studies in MPhil and PhD programs from private and public colleges and universities of Lahore city. Purposive sampling method was used that is useful in exploratory qualitative research, with limited means, as well as in the research where a single case (or small number of cases) can be significant in explaining the concerned issue. Thus, from four universities; two public and two private from Lahore, sample was drawn.

\subsection{Instrumentation}

Instruments used for this research are semi-structure open ended interview comprised of ten questions. The first three questions were designed to know about the reasons of returning to education and the personal goals towards education from the respondents. Whereas, next two questions were used to explore the needs of adult differ from young students and the hindrance they faced during their course in university.

Other two questions were to investigate the concept of transformation through learning and experiences for transformative learning interventions by respondents during their course in university. 


\section{Review of Economics and Development Studies, Vol. 6 (2) 2020, 391-40o}

The determination of arranging the unrestricted response interrogations was to collect further more records from participants to spread the results with more comprehensive view. Interviewees were required to make available and shared a brief description about their experiences having transformative learning interventions during their course.

\subsection{Data Analysis and Findings}

On the bases of analyzed data following findings have been made that one who describe the happening of transformational learning, she must have the indication of change. The outcomes from the data analysis identified that all 16 of the participants in the study fixed change their opinions in some form or reshape their beliefs or ideas as an outcome of experiencing the Transformative learning interventions in universities during their course. However, not all of the students' thinking, beliefs and behaviors were transformed but all the participants discovered and expressed significance as a minimum in one of the Transformative learning strategies.

Through critical reflection on their suppositions, beliefs and implementation on the experiential, transformational and andragogical strategies that defined enable many of the adult learners to modify their "meaning schemes" and transform their viewpoints. They developed their "emotional muscle" and started to admire and value their personal world of ideas and beliefs. Some experiences were significant to certain individuals for specific reasons wherein the motivation towards education is substantial. Brown (2008) clarified that firstly, the significance of experience is repetitive and examined through students' experiences in a series of events related to education that happen in a planned and controlled way. Secondly, the effect of critical reflection is discovered through students' experience and involvement in variety of panels. In lastly, the active participation of students in semi-structured and open-ended interviews reflected the concept of rational discourse.

The outcomes from the participants of this study mentioned that the involvement of both inservice education students and educators considering education as a professional development, experienced perception of transformation as a consequence of their experiences in the transformative classroom. The latest study explained that these effects are maintained and expanded the essentials to deliver educational institutions and their personnel with the consideration in the varieties of professional development practices that possibly will transform educators (King, 2004). Consideration discovered that a most of the partakers experienced perspective transformative through interventions during the study and the participants found changes in attitudes and behavior towards themselves and others in their reflective situations, and in their understanding of other's views on every day related concepts. The participants pointed out that the modifications were influenced by the university teacher's support, solution of the challenges, discussions on global topics, reflection through journals, class activities and personal rational discourses.

\section{Discussion}

The discussion part is organized around the findings relating to the research questions. The discussion is based on the findings with the intention of synthesizing into cohesive vision from the female adult learner's experience of receiving Transformative learning interventions and motivation related events during study.

\subsection{Reasons of Returning to Education of Adult Students}

The first research question was to describe the reasons of returning to education of adult students? Many of the respondents defined their reason for returning to education was for career development and advancement of their professional position. They classified and addressed the needs of 


\section{Review of Economics and Development Studies, Vol. 6 (2) 2020, 391-40o}

adult students in higher education for returning to educational formal institute for the purpose of proceeding their degree, and focused on the promotion for the job category meant dedication to an organization for a long timeframe within one's career. Few of them described their reason for continuing was to become competent and perfect with requirement of modern world and globalization. The respondents also mentioned that they work on self-identity by having the higher education degree adult students make their identities as learners together with other adult individualities (Johnston \& Merrill, 2009). For the attainment of their selected academic and personal outcomes, students have to familiarize with the change in their institutions and transformation of practices for the promotion in their learning identities.

\subsection{Hindrances faced by the adult students in higher studies}

The discussion further moves with the second research question that is what are the hindrances faced by the adult students in higher education? Research findings with the help of responses from the interviewees have clearly explained the sense of the hindrances they perceived as during the course in the university. The hindrances described by the respondents were time management, attendance, relationship with young fellows \& teachers, financial issues, workload of assignments and the responses of administration on sensitive matters and these are in line with Cross (1981).

The most common hindrance faced by the students was time management. There was a noteworthy time requirement for attending the lectures. Working full-time and or had family responsibilities and a learner has a smaller amount time she will have for university work with more external commitments and this can reason for developing stress. All the participants reported having difficulty in maintaining time management between job and university.

The next hindrance reported by majority of the respondents was maintaining attendance. Most of the adults who were willing to learn were on the job. Due to the busy schedule in their work place, it was impossible to them to attend an educational institution regularly. Sometime due to certain personal reasons or troubles, they were unable to attend the university. Their busy schedule may not allow them to attend consistently the University.

Majority of respondents described their financial issues as the hindrance they faced. Majority of the interviewees were financially independent and they were paying the fees by themselves. The fees that the students had to pay were quite high and for those working they had to save some amount their salary monthly because they had to pay their fees per semester. Furthermore, students needed to pay it at one time once the semester starts which means they would need to prepare a large amount of money at one time as there were no payment installment schemes for it. On the other hand, there were no scholarships for adult students; some private universities offered the merit-based scholarship to the respondents but in the first semester it was rejected with the obligation of lower achievement ranking in assignments.

\subsection{Needs of Adult Student are Different from the Young Student}

Furthermore, the next research question was to explain the needs of adult student are differ from the young student? Most of the participants explained that the needs of the adult student were differed significantly from the young class fellows. Many of them mentioned that the teaching methods and practices for adult learners were different as for the younger students. There was no report of problems between the adults and younger learners they did not mix. Although there was logic behind in the mind of adult students that colleges and universities are mainly structured for young students so they had no issue with that. Being as an active student, there was a clear difference between these 


\section{Review of Economics and Development Studies, Vol. 6 (2) 2020, 391-40o}

learners and it was explained by most of the participants that the young students were more energetic and had a lot of time as compare to the adult students. Some respondents mentioned their age as a disadvantage for causing them less energetic and faced difficulties in external commitments. On the contrast, some participants explained that they had significant benefit over the younger students in the way that they had more life experience and working skills to take along with the course. Some mentioned they were capable to prepare for the course for satisfaction instead of having the pressure of receiving qualification promotion or upgrading the employment designation.

\subsection{Transformative Learning and its Conceptual Understanding}

The important area of the research comprises around this question of research that what are Transformational Learning and its conceptual understanding?

Most of the interviewees described that they had a clear idea about the Transformative Learning. They reflected that it is used to transform the ideas and views on different issues, beliefs and topics. Their beliefs, opinions, views and expressive responses facilitates to organize the meaning structures with the frames of reference based upon our experiences within our cultural perspective, that effect on how we understand and respond to events in our lives.

Some respondents described the Transformative Learning enhance our ability to understand and consider broader options and possibilities in our interactions. It encourages the practices in solving problems from different viewpoints. The aim is to generate integrated group of learners who shared experiences of activities to make meaning of their life experience.

The two of the participants were not able to defined the transformative learning but they had knowledge about its interventions with the simple name "learning" and "change in behavior".

\subsection{Experiences of Adult Learners of Transformative Learning Interventions During The Course}

This research question is related to the previous question that focuses on to describe the experiences of Transformative Learning Interventions during the course for adult learner? The experiences of the respondents described that it is essential that the learners are willing to attend and listen to others, in order to reinforce relations that recognize and encourage the acceptance of differences among the participants, as well as their similarities. The majority of the participants experienced their engagement in seminars only for listen the information of the experts; there was no opportunity given for participation. Some of them experienced educational conferences with high fees. Some of them pointed to presentation; individually and in group. Few of them described discussions in their experiences. Few of them described that the formation of an opinion through articles reviews on social and critical issues during their course.

\subsection{Conducive Environment for Effective Learning for Adult Learners}

The important point related to the objective of thesis was to define Conducive environment for effective learning for adult learners? Conducive learning environment is known as the atmosphere of the educational setting that make available conditions for making the learning process easy and interesting for the participants to work efficiently. Conducive learning environment satisfies the needs of the participators for not only in the attainment of numerical competence. The participants defined the Conducive environment in terms of physical facilities, relaxation in time, attendance and assignments, effective communication with teachers and young students and suitable teaching methods \& practices for adults. 


\section{Conclusion and Recommendations}

There are some recommendations for further study based on the research findings that a comparative study on the bases of gender could be conducted between the contributors who involved with transformational interventions and the contributors who did not experienced. This comparison will be significant for understanding the effectiveness of transformation in learning with the help of interventions for adult learners.

Moreover, public and private institutions should have taken steps to serve adult learners and there will be a need for leadership and support from government to make adult learners viewed on the higher priority in several campuses. Institutions should arrange events for engaging students in reflective writing and speaking activities that encourage participation on the real-life issues they experienced.

The adult educators should have struggled to maintain a good rapport and relationship with the adult learners during the presentation of transformative learning interventions. This will stimulate the interest of the learners in the learning environment and process on the effective learning targets to be achieved. The adult facilitators employed would be skilled, qualified and expert for handling the transformative learning interventions for adult learners. This will provide them the opportunity to use reflective strategies with andragogical method in the learning situation to make the teaching learning process more effective. The Higher education and academic staff struggle to nurture the transformative learning environment which is supportive, empathetic and favorable to enhance transformative learning in adult learners.

\section{References}

Aslanian, Carol B., and Henry, M. Brickell. (1990). Americans in Transition: Life Changes as Reasons for Adult Learning. New York: Colleg Entrance Examination Board.

Bjorklund, B. R., and Bee, H. J. (2008). The journey of adulthood. (6th ed). Upper Saddle River, NJ: Pearson/Prentice Hall.

Blake, J. (2008). UNESCO's 2003 Convention on Intangible Cultural Heritage: The implications of community involvement in 'safeguarding'. In Intangible heritage (pp. 59-87). Routledge.

Brown, K., \& Rutter, L. (2008). Critical thinking for social work. SAGE.

Bryman, A. (2012). Social research methods (4th ed.). Oxford: Oxford University Press.

Cranton, P. (2006). Understanding and promoting transformative learning: A guide for educators of adults. San Francisco: Jossey-Bass.

Creswell, J. W. (2003). Research design: A qualitative, quantitative, and mixed method approaches (3rd ed.). Thousand Oaks, CA: Sage.

Creswell, J. W. (2009). Research design: Qualitative, quantitative, and mixed methods approach (3rd ed.). Thousand Oaks, CA: Sage.

Creswell, J. W., and Plano Clark, V. L. (2011). Designing and conducting mixed methods research (2nd ed.). Thousand Oaks, CA: Sage.

Cross, K. P. (1981). Adults as learners: Increasing participation and facilitating learning. San Francisco, CA: Jossey-Bass.

Field, J., Künzel, K., \& Schemmann, M. (2016). International Comparative Adult Education Research. Reflections on theory, methodology and future developments. Internationales Jahrbuch der Erwachsenenbildung, 39(1), 109.

Johnston, \& Merrill, B. (2009). Developing learning identities for working class adult students in Higher Education: The role of identity and learning careers in adult education (pp. 129-144).

Khalid, M.U. (2008). Creating a learner-friendly environment in all adult and non-formal education 
literacy center: Journal of Nigeria National Council for Adult Education. (NNCAE) pp.151-158).

King, N. (2004). Using templates in the thematic analysis of text. Essential guide to qualitative methods in organizational research, 2, 256-70.

Lehman, M. A. (2003). Interrupting the reflective practitioner: discovering the espoused philosophies and theories and theories-In-Use of 13 Adult Educators (Doctoral dissertation, The Ohio State University).

Merriam, S.B., and Brockett, R.G. (2007). The profession and practice of adult education: An introduction. San Francisco: Jossey-Bass.

Mezirow, J. (1991). Transformative Dimensions of Adult Learning: San Francisco, CA: Jossey-Bass.

Mezirow, J. (1994). Understanding transformation theory: Adult Education Quarterly 44(4): pp. 222232.

Mezirow, J. (1997). Transformative learning: theory to practice. New Directions for Adult and Continuing Education.no.74, summer 1997. Jossey-Bass Publishers.

Reay, D. (2002). Class, authenticity and the transition to higher education for mature students: The Sociological Review, 50, pp. 398-418

Taylor, E (1998). The Theory and Practice of Transformative Learning: A Critical Review. Ohio: Ohio State University

Veedross, A. (1966). Jus dispositivum and jus cogens in international law. American Journal of International Law, 6o(1), 55-63.

Yin, R.K., (2001). Case Study Research: Design and Methods, third ed. Sage, London. 